\title{
Aplicação do Kahoot e do Quizizz para otimizar engajamento nas disciplinas de metodologia de pesquisa
}

\author{
Lafayette B. Melo ${ }^{1}$ \\ ${ }^{1}$ Unidade Acadêmica de Informática - Instituto Federal da Paraíba (IFPB) \\ CEP 58015-435 - João Pessoa - PB - Brazil \\ lafayette.melodacademico.ifpb.edu.br
}

\begin{abstract}
This article shows an application of the Kahoot and Quizizz tools in disciplines of research methodology of technological courses of computation. The work was developed from a case study during a school period and involved the design of gamification for the organization of classes. The process was accompanied by notes, a Facebook group, tools registers and a questionnaire to get information on better uses of these tools, their strategies, and new uses. It was concluded that the strategies were satisfactory for the audience, with greater motivation of the participants, but that new activities and resources should be better explored.
\end{abstract}

Resumo. Este artigo mostra uma aplicação das ferramentas Kahoot e Quizizz em disciplinas de metodologia de pesquisa de cursos tecnológicos de computação. $O$ trabalho foi desenvolvido a partir de um estudo de caso durante um período letivo e envolveu estruturação de gamificação para organização das aulas. O processo foi acompanhado por anotações, um grupo no Facebook, registros das ferramentas e um questionário, para obter informações sobre melhores usos dessas ferramentas, suas estratégias e novos usos. Conclui-se que as estratégias foram satisfatórias para o público, com maior motivação dos participantes, mas que novas atividades e recursos deveriam ser mais bem explorados.

\section{Introdução}

O uso de metodologias ativas está aumentando com o apoio de ferramentas computacionais. Guimaraes et al. (2018) tratam como aliar métodos ativos com tecnologia e citam o estudo de caso como modo apropriado para resolução de um ou mais casos específicos. Licorish et al. (2017) apresentam o Kahoot ${ }^{1}$ como ferramenta de metodologia ativa e justificam a abordagem de estudos de caso pelo fato de em geral os fenômenos estudados não serem bem distinguíveis dos limites contextuais observados.

Pesquisas como as de Licorish et al. (2017) e Ribeiro et al. (2018) se baseiam em noções de Wang (2015), que criou o conceito Game-Based Student Response Systems (GSRS), o qual consiste na utilização de gamificação em jogos de perguntas e respostas interativos aplicados pelo professor para competição entre os alunos, como

${ }^{1}$ https://kahoot.com/ 
VIII Congresso Brasileiro de Informática na Educação (CBIE 2019)

Anais dos Workshops do VIII Congresso Brasileiro de Informática na Educação (WCBIE 2019)

ocorre no Kahoot. Há várias pesquisas sobre o uso de GSRS, especialmente o Kahoot, mas há outras ferramentas, como o Quizizz ${ }^{2}$, que utilizam conceitos semelhantes.

Este trabalho faz uso do Kahoot e do Quizizz, de forma exploratória, em disciplinas de metodologia de pesquisa, no contexto real do desenvolvimento de um período letivo em cursos tecnológicos de computação. Investiga-se o "como" e o "por que" dos melhores usos dessas ferramentas, suas estratégias e novas formas de uso.

\section{Métodos}

O trabalho foi desenvolvido com quatro diferentes turmas. O estudo de caso como metodologia, conforme Yin (2013), foi adequado, por tratar de aspectos contemporâneos (as coletas foram concomitantes ao desenvolvimento das disciplinas), reais (cada uso foi feito ao final de cada aula para testar conteúdos lecionados) e pretendeu-se investigar limites ainda não claramente definidos - como ferramentas GSRS podem ser melhor introduzidas em computação em disciplinas de metodologia de pesquisa. O pesquisador estava imerso como professor das disciplinas. Durante o desenvolvimento da pesquisa, havia algumas especificações como descrito a seguir.

\subsection{Estruturação das ferramentas para o processo de gamificação}

Faria (2016) faz uso do Kahoot e aponta técnicas para implementação efetiva da gamificação no ensino GSRS, as quais são assim aproveitadas neste estudo: pontos (aparecem após cada pergunta e ao final surgem com novos números com a classificação geral), medalhas (representação visual do que foi alcançado com classificações em tabelas, barras de progressão, pódios etc.) e mecânica - que é o processo comportamental do jogo; neste caso a competição individual. Na figura 1, são mostradas duas telas do Kahoot, a primeira da perspectiva do professor, que projeta a imagem para toda a turma com as questões e suas alternativas e, a segunda, da perspectiva do aluno, que por meio do celular ou de computador escolhe a alternativa correta. De modo semelhante, temos a figura 2, em relação ao Quizizz, mas a primeira tela do professor, que é projetada, apresenta apenas barras de progressão de cada aluno. Pontos e mecânica são utilizados nas duas ferramentas, mas em ordens e tempos diferentes. As medalhas são específicas de cada uma (em tabelas com colocações após cada pergunta e pontuação final dos três melhores, mostradas em pódios, no Kahoot, e barras de progressão de cada um com medalhas para as posições, no Quizizz).

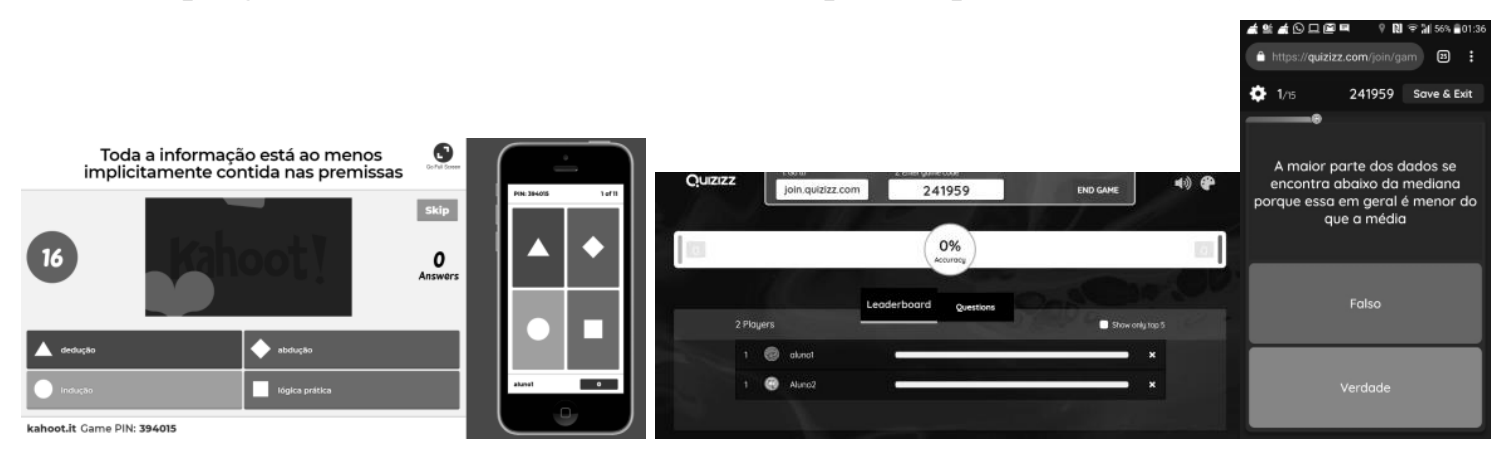

Figura 1. Kahoot

Figura 2. Quizizz

${ }^{2}$ https://quizizz.com/ 
VIII Congresso Brasileiro de Informática na Educação (CBIE 2019)

Anais dos Workshops do VIII Congresso Brasileiro de Informática na Educação (WCBIE 2019)

\subsection{Organização da aplicação no período letivo e conteúdo abordado}

Os alunos optavam por usar no computador ou nos seus celulares. Em quase todas as aulas foram utilizadas as ferramentas de modo intercalado, para que cada uma tratasse metade do conteúdo. Todos os desafios ocorreram ao final da aula e a maioria envolvia entrega de prêmios como lanches ou material de escritório. As aulas foram lecionadas para duas turmas de "Métodos e Técnicas de Pesquisa" - dos cursos tecnológicos de Sistemas para Internet (17 alunos) e Redes de Computadores (6 alunos), uma de "Fundamentos de Metodologia" - Sistemas para Internet (23 alunos), e uma de "Produção Textual Técnico-Científica" - Redes de Computadores (42 alunos). Os conteúdos envolviam lógica e pensamento científico, como fazer um projeto, estudo de caso, levantamentos, leitura e escrita de um artigo, estatísticas em pesquisa etc., com níveis mais avançados, conforme a disciplina.

\subsection{Anotações, Facebook, registro nas ferramentas e questionário}

Para triangulação dos dados, usou-se as seguintes fontes: escrita de sugestões dos alunos das aplicações com as ferramentas, comentários que os alunos fizeram em grupo do Facebook, resultados cadastrados com as ferramentas e um questionário ao final para medir a satisfação e comparar com os dados obtidos anteriormente.

\section{Resultados e discussão}

A maioria das sugestões registradas envolvia aumentar o tempo de resposta no Kahoot e dar um tempo maior total para uso do Quizzis. Eventualmente, reclamava-se da interpretação de um enunciado e alguns alunos manifestaram opção por uma ou outra ferramenta. Isso sugere que modificações para melhoria de ambos os usos residia mais no modo como o professor elaborou as perguntas e escolheu determinados recursos do que nas ferramentas em si. As postagens no Facebook sempre envolveram manifestações dos alunos: "professor, hoje as perguntas vão ser mais fáceis?", "galera, a premiação vai ser um carro!", “Agora vai”, "Kahoot, kahoot, kahoot!", "professor, não esqueça de trazer os prêmios que esqueceu semana passada" etc. De todo modo, as postagens acompanhadas de fotos dos prêmios, apesar de gerarem uma expectativa de maior participação, serviram mais para gerar um ambiente de descontração, pois confrontando tais postagens com os registros de participação, não houve diferença em relação aos momentos nos quais não houve entrega de prêmios. Ademais, nas sugestões ao final da aula, muitos se manifestaram por usar as ferramentas sempre, mesmo sem premiação. A partir dos registros nas ferramentas, pôde-se identificar que os primeiros lugares eram basicamente os mesmo em cada turma.

O questionário mostrou que $72 \%$ dos alunos preferiram o Kahoot e $28 \%$, o Quizizz. Nenhum dos respondentes usou a opção "não sei responder". A maioria dos respondentes $(80 \%)$ foi da disciplina de "Produção Textual Técnico-Científica" do curso de Redes, o que era esperado pelo fato de ser uma turma maior do que as demais. Sobre motivação, $86 \%$ responderam que as aplicações motivaram as participações na disciplina e $14 \%$ responderam que não. Na pergunta sobre modos de uso da ferramenta, com opções inclusivas, obteve-se: $100 \%$ escolheram "ao final das aulas testando os conhecimentos", 43\% escolheram "como estratégia para revisão de estudos", $0 \%$ escolheu "no início das aulas para verificar o conhecimento" e $0 \%$ escolheu "como testes ou provas". A escolha simultânea das duas primeiras opções sugere manter o uso ao final das aulas, mas também preparo de material para os alunos fazerem revisões. $\mathrm{Na}$ 
resposta à pergunta aberta sobre outras formas de uso, pediu-se que fosse mantido o uso das duas plataformas e não só uma para que as aulas ficassem diferenciadas, que fossem aplicados ou criados outros jogos e que houvesse desafios também sobre os próprios projetos que os alunos desenvolviam nas disciplinas.

Confrontando o questionário com as outras fontes de dados, pode-se inferir que, apesar de sempre haver manifestações de preferência sobre o Kahoot ou o Quizzis, há uma necessidade de se manter as duas. Sugere-se estudo por parte do professor de melhoria e criação de novas atividades (sobre os projetos). A maneira de fazer o acompanhamento das aulas não foi mencionada no questionário o que indica sua continuidade, mas compartilhando os registros das ferramentas com os alunos para pontuar de forma cumulativa o que foi feito no período letivo e não apenas em cada aula.

\section{Conclusões}

O trabalho mostrou que estratégias GSRS são válidas, independentemente da ferramenta, cada uma com suas técnicas de pontuação, medalhas e mecânica - que pode ser definida pelo professor. O uso de ferramentas para disciplinas que envolvem conteúdo de metodologia de pesquisa, para um público tecnológico com aversão por conteúdos que não sejam de práticas de computação, também pareceu apropriado, pois os desafios versavam sobre problemas comuns nos projetos das disciplinas, o que ajudou sua execução de forma consciente. Outras pesquisas podem ser feitas para outros conteúdos disciplinares com este formato e novas formas de aplicação envolvem agregar uma nova ferramenta ou método ativo para investigar em conjunto com o que foi aplicado. Também sugere-se um treinamento ou estudo mais aprofundado das ferramentas para sua melhor exploração por parte dos professores.

\section{Referências}

Faria, V. P., Costa, H., Júnior, P. A. P. (2016). eQuest: Um Sistema de Resposta para Estudantes Gamificado. In Anais dos Workshops do V Congresso Brasileiro de Informática na Educação (CBIE 2016), p. 280-287.

Guimarães, F. T., Leite, M. D., Reinaldo, F. e Ito, G. (2018). Métodos ativos de ensino aliados com tecnologia para a prática de ensino: um relato de experiência. In Anais do XXIV Workshop de Informática na Escola (WIE 2018), p. 333-342.

Licorish, S. A., George, J. L., Owen, H. E. e Danie, B. (2017). “Go Kahoot!” Enriching Classroom Engagement, Motivation and Learning Experience with Games. In Proceedings of the 25th International Conference on Computers in Education, p. 755-764.

Ribeiro, R. P., Souza, A., Barcelos, T. e Silva, L. A. (2018). Mensurando o desenvolvimento do Pensamento Computacional por meio de Mapas AutoOrganizáveis: Comparação de métricas de complexidade de Software com Dr. Scratch e CT-Test. In Anais dos Workshops do VII Congresso Brasileiro de Informática na Educação (WCBIE 2018), p. 609-618.

Wang, A. I. (2015). The wear out effect of a game-based student response system. In Computers \& Education, 82, p. 217-227.

Yin, R. K. (2013). Case study research: Design and methods. Sage publications. 